\title{
Las exportaciones de plátano como una estrategia de desarrollo rural en Colombia
}

\author{
Banana Exports as a Rural Development \\ Strategy in Colombia
}

\section{Exportação de banana como estratégia de desenvolvimento rural na Colômbia}

\author{
Marcela Carvajal García* \\ Paula Zuluaga Arango** \\ Olga Lucía Ocampo López ${ }^{* * *}$ \\ Daniela Duque Gómez ${ }^{* * * *}$
}

Fecha de envío: 5 de septiembre de 2018

Fecha de aceptación: 30 de abril 2019

Cómo citar este artículo/ To reference this article / Comment citer cet article / Para citar este artigo:

Carvajal-García, M., Zuluaga-Arango, P., Ocampo-López, O. \& Duque-Gómez, D. (2019). Las exportaciones de plátano como una estrategia de desarrollo rural en Colombia. Apuntes del CENES, 38(68), 113 - 148. https://doi. org/10.19053/01203053.v38.n68.2019.8383

* Magíster en Administración de Negocios. [1], [2]. marcelacarvajal@autonoma.edu.co (6) https://orcid. org/0000-0001-5780-135X

** Magíster en Administración. [1], [2]. pzuluaga@autonoma.edu.co B https://orcid.org/0000 -0002-4248-562XA

*** Ph.D. en Ingeniería. Profesora Facultad de Ingeniería [2]. olocampo@autonoma.edu.co Q https://orcid.org/0000-0002-6394-977X

**** Profesional en Negocios Internacionales. Profesional de apoyo [2]. danieladuquegomez@gmail.com (6) https:// orcid.org/0000-0002-5024-0219

[1] Profesora Facultad de Estudios Sociales y Empresariales, Departamento de Administración y Economía.

[2] Universidad Autónoma de Manizales, Colombia. 


\section{Resumen}

Este artículo busca identificar oportunidades en mercados internacionales para el plátano fresco y transformado de origen colombiano, a partir del análisis de información obtenida de fuentes secundarias en el que son analizadas las variables de tendencias de consumo, estadísticas de producción, exportación e importación, normativa, restricciones y requisitos técnicos, para el periodo 2013-2017, a las cuales son aplicados los criterios de clasificación de los modelos Uppsala y Vernon. Se identifican los productos con mayor demanda y los países con superior probabilidad de acceso, como propuesta para su incorporación en la estrategia competitiva para los productores y transformadores de plátano en Colombia. El estudio concluye que el producto en fresco presenta una demanda significativa, al igual que productos transformados como plátano congelado, chips y harina de plátano, que pueden ser comercializados con mejores resultados en el mercado norteamericano y europeo.

Palabras clave: competitividad, desarrollo rural, internacionalización, plátano, política comercial.

Clasificación JEL: F02, F13, O02, O54, R00, R11. 


\begin{abstract}
This article seeks to identify opportunities in the international markets for fresh and processed Colombian plantain, from the analysis of the information obtained from secondary sources in which the consumption variables, production statistics, exports and imports, regulations, restrictions and technical requirements are analyzed for the period 2013-2017, to which the classification criteria of the Uppsala and Vernon models are applied. We identify products with higher demand and the countries with higher probability of access, as a proposal for their incorporation into the competitive strategy for plantain producers and companies in Colombia. The study concludes that the fresh and processed products such as frozen plantain, chips and plantain flour present a significant demand, which can be marketed with better results in the US and European markets.
\end{abstract}

Keywords: competitiveness, rural development, internationalization, plantain, comercial policy. 


\section{Ressumo}

Este artigo procura identificar oportunidades em mercados internacionais para a banana colombiana fresca e transformada, a partir da análise das informações obtidas a partir de fontes secundárias, nas que são analisadas as tendências variáveis de consumo, estatísticas sobre a produção, exportação e importação, regulamentos, restrições e requisitos técnicos, para o período 2013-2017, aos quais são aplicados os critérios de classificação dos modelos Uppsala e Vernon. Os produtos com maior demanda e os países com maior probabilidade de acesso foram identificados como uma proposta para sua incorporação na estratégia competitiva para produtores e empresas de banana na Colômbia. O estudo conclui que o produto fresco apresenta uma demanda significativa, bem como produtos processados como banana congelada, chips e farinha de banana, que podem ser comercializados com melhores resultados nos mercados norte-americano e europeu.

Palavras chave: competitividade, desenvolvimento rural, internacionalização, banana, política comercial. 


\section{INTRODUCCIÓN}

Las características de la agricultura colombiana asociada a la disposición de sus suelos, las particularidades de la tierra y la disponibilidad de recursos naturales, han marcado una ventaja estratégica en el desarrollo del sector. El potencial productivo, analizado por Fedesarrollo en las políticas para el desarrollo de la agricultura, indica que puede mantener el equilibrio en la demanda de alimentos locales y unas ganancias proyectadas para los agricultores, basadas en la exportación de productos competitivos en el mercado internacional (Perfetti, Balcázar, Hernández \& Leibovich, 2013).

El análisis de comportamiento y aporte al PIB durante el 2017, según las cifras del DANE, mostró que el conjunto de elementos agropecuarios aumentó en un $4.9 \%$ comparado con el 2016, basado en el crecimiento de los cultivos de productos no tradicionales, especialmente en cultivos permanentes con un aporte del $8.9 \%$ y de cultivos transitorios en $8.1 \%$ sobre el total de cultivos (2018). Estas cifras, a pesar de mostrar un comportamiento positivo, exponen que su participación no refleja un comportamiento significativo dentro los indicadores macroeconómicos nacionales y regionales, debido a su baja competitividad en los mercados globalizados que manifiesta estrategias de bajo alcance en los análisis de comercialización de los productos.

Así, el cultivo de plátano en Colombia hace parte del sector calificado de acuerdo con Conecta Rural (2009) como uno de los cultivos permanentes que tiene mayor presencia en el sistema económico campesino y cuyo producto es de importancia para la alimentación de los colombianos, con un consumo per cápita aproximado de $155 \mathrm{~kg}$ al año 2009. Igualmente, el Ministerio de Agricultura y Desarrollo Rural (2016) a través de AGRONET, reporta que para el 2016 la producción total de cultivos de plátano en Colombia ascendió a 3684 $344 \mathrm{t}$, de las cuales el departamento de Caldas registra una producción de 231 204 t, que significa una participación del $6.28 \%$ del total nacional, y siendo 
el departamento de Antioquia el más representativo con una tasa mayor al $40 \%$. A pesar de ello, se presentan unas condiciones nacionales precarias para el campesino, donde se identifican dificultades de acceso a servicios de salud y educación, sumadas a una deficiente infraestructura vial secundaria y terciaria, que han retrasado el desarrollo rural y la incursión de los productos en los mercados globalizados (Macías, 2016). De esta manera, limitaciones asociadas a la baja incorporación de tecnologías en la producción, mínima tasa de formación empresarial y comercial, poco volumen de producción y deficiencias en calidad de producto, se suman al desconocimiento del mercado internacional, lo cual ha restringido las posibilidades de crecimiento (Macías, 2016).

En contraste, investigaciones realizadas por los ministerios de Agricultura y Desarrollo Rural, y de Comercio, Industria y Turismo, identifican 26 productos con potencial exportador para el país, en la búsqueda de la diversificación y admisibilidad de alimentos en mercados internacionales, dentro de los cuales se encuentra el plátano (Redacción El Tiempo, 2017); por lo que se concentra un especial interés en el desarrollo del mercado de este producto con potencial exportador, que puede generar impacto positivo en los indicadores económicos $\mathrm{y}$, en especial, en el mejoramiento de las condiciones de vida para el campesino colombiano.
En la búsqueda de este objetivo y como estrategia para el cierre de brechas competitivas, productivas y de sostenibilidad, el Gobierno nacional crea el Sistema Nacional de Innovación Agropecuaria (SNIA) a través de la Ley 1876 de 2017, que plantea la implementación de acciones de investigación, desarrollo tecnológico, transferencia de tecnología, gestión del conocimiento, formación, capacitación y extensión, que puedan soportar de manera estructural los procesos de innovación demandados por el sector agropecuario colombiano. En consecuencia, se crean las mesas de Ciencia, Tecnología e Innovación Agropecuaria como actores fundamentales del SNIA, cuya función es articular a los actores locales entendidos como organizaciones de productores, centros de investigación y desarrollo tecnológico, instituciones de educación superior y entidades sectoriales de nivel territorial, en beneficio de la productividad, competitividad y sostenibilidad (Congreso de Colombia, 2017).

Por ende, la estrategia de articulación para avanzar en la competitividad incluida en la agenda integrada de competitividad del departamento de Caldas y el municipio de Manizales, ha logrado consolidar las mesas de competitividad desde el 2014 y enfocar sus esfuerzos en los sectores productivos de mayor influencia, donde prevalece el enfoque agrícola, especialmente en lácteos, cítricos, café y plátano, como mercados de priorización, que han requerido interés en mejoramiento productivo, técnico 
y comercial por su alto potencial de crecimiento e impacto en la comunidad campesina. Por lo tanto, al encontrar que este sector ha requerido mayor conocimiento empresarial y comercial que ayude a identificar estrategias para la diversificación de su portafolio con valor agregado y mejora de procesos de comercialización de productos frescos $\mathrm{y}$ procesados en mercados internacionales, se generan alianzas con los diferentes actores que puedan contribuir con este proceso y permitan aprovechar las oportunidades en los mercados internacionales del plátano que potencien el desarrollo rural, regional y nacional.

Es por esto que esta investigación se realizó como plan de acción de la mesa para la competitividad de musáceas, en el marco del Macroproyecto de Investigación y Desarrollo "Fortalecimiento del sector musáceas en Manizales, Caldas", financiado por la Secretaría de TIC y Competitividad de la Alcaldía de Manizales y la Universidad Autónoma de Manizales, para la identificación de mercados potenciales internacionales de productos asociados al plátano con viabilidad exportadora, enfocado en las condiciones del fruto obtenido en el municipio de Manizales y el departamento de Caldas durante el periodo 2013-2017.

Teniendo en cuenta lo expuesto, el artículo plantea en primera instancia los fundamentos teóricos relacionados con la competitividad de los mercados agrícolas, la comercialización internacional de sus productos y los modelos utilizados para su implementación. Posteriormente, la clasificación de países a través de las variables planteadas por el modelo Uppsala y el ciclo de vida del producto de Vernon, aplicadas en tres fases, y finaliza con la presentación de resultados para la elección de los mercados destino con mejores posibilidades de comercialización y que presentan un acceso a corto, medio y largo plazo para el campesino, de acuerdo con las condiciones de producto actual y su mejoramiento continuo según las reglamentaciones vigentes, calidad de producto y demanda de mercado.

\section{FUNDAMENTOS TEÓRICOS}

La competitividad ha sido un tema tratado desde los autores económicos clásicos que buscaban el mejoramiento de ventajas comparativas entre naciones. De ahí que actualmente se generen diferentes dimensiones de análisis que tienen en cuenta enfoques macroeconómicos, formulación de políticas industriales y análisis desde entorno empresarial (Rodríguez, Baca, Santoyo \& Reyes, 2013). El planteamiento de Porter (1998), basado en la propuesta desde su diamante y las fuerzas que lo conforman, analiza la influencia de cada uno de ellos sobre su desempeño en el mercado y, a su vez, cómo se interrelacionan para conformar los eslabones que fortalecen un determinado mercado. Este proceso constituye la cadena de valor, conformada por el engranaje de cada una de las actividades necesarias para producir un bien o servicio, desde 
su origen, pasando por cada una de las fases de producción, hasta el consumidor final (Campero, 2015).

Este concepto fue apropiado para el sector agrícola con la incursión de las concepciones de "agronegocios", buscando la conjugación de las actividades rurales y los procesos asociados con la oferta de sus productos a los consumidores finales (Zurbriggen, 2015). Así, su aplicación ha sido cada vez más aceptada en los países con mayor influencia agrícola y adoptada como metodología que busca impulsar diferentes modelos de competitividad y mejorar las condiciones de vida del productor. De allí que sea forjado el fomento hacia la asociatividad de las empresas y de manera especial las mipymes, como estrategia fundamental para el desarrollo económico y empresarial, a través de la conformación de clústeres y encadenamientos productivos que aceleran elementos de productividad y competitividad de diferentes países (Bada, Rivas \& Littlewood, 2017).

En consecuencia, Castro (2007) señala que la aplicación de los encadenamientos productivos debe iniciar con la búsqueda del fortalecimiento del ambiente empresarial, elemento que permite adaptarse y competir en un entorno globalizado y exigente. Estos elementos se logran a través de la integración productiva que facilita la elaboración de políticas de desarrollo y fortalece la relación universidad-empresa-Estado (Bada et al., 2017).
De igual manera, se hace necesario identificar y analizar los modelos de internacionalización que han sido aplicados en las investigaciones empíricas y que han mostrado un mejor desempeño en sus usos y resultados. De acuerdo con la revisión de literatura realizada por Cardozo, Chavarro y Ramírez (2013), se identifican tres grupos principales que han obtenido mejores resultados y se clasifican como modelos pioneros, de segunda generación y modelos contemporáneos.

Los modelos pioneros, entendidos como aquellos que han sido abordados desde la perspectiva económica, incluyen la teoría de la organización industrial, la teoría de la internacionalización y el paradigma ecléctico de Dunning, desde una perspectiva macroeconómica, los cuales explican las razones por las cuales una empresa busca la expansión internacional y las condiciones que influyen en la localización de sus operaciones, así como las ventajas de costos y estructura del mercado (Trujillo \& Guzmán, 2015). De la misma manera, desde la perspectiva de análisis de proceso, son incluidos el modelo Uppsala de la escuela nórdica, la planeación sistémica y el modelo del ciclo de vida de Vernon (Cardozo et al., 2013), caracterizados por estar basados en aprendizaje incremental apoyado en experiencias y experimentaciones que logran mejor desempeño por su simplicidad en la aplicación de un proceso de crecimiento internacional. Por su parte, los modelos clasificados en la categoría segunda 
generación son entendidos como una secuencia metodológica y proyectada de cada una de las actividades, que facilitan la incursión en el mercado internacional de manera tal que el avance de cada una de las etapas significa un nivel superior en las prácticas administrativas. A este grupo pertenecen el modelo de innovación y el modelo híbrido, los cuales consideran relevantes aspectos como tecnología, innovación, experiencia, acceso a nuevos mercados y conocimiento del consumidor (Cardozo et al., 2013). Por último, los modelos contemporáneos están compuestos por el modelo de redes y el modelo holístico, los cuales surgen como respuesta a los cambios generados en la sociedad del conocimiento para adaptarse al trabajo colaborativo (Stewart, 1998). En esta clasificación, las empresas pueden desarrollar ventajas y rentabilidad basadas en el conocimiento, mediante el fortalecimiento de relaciones con organizaciones líderes en el exterior, que les permiten acceder a tecnologías avanzadas y aprendizajes experienciales de los procesos de internacionalización (Casson \& Wadeson, 2017).

De acuerdo con el contexto de estudio, se analizan con mayor profundidad los modelos correspondientes a la perspectiva económica desde el ámbito de procesos, teniendo en cuenta la facilidad de acceso a su aplicación, así como la baja tecnificación del sector agrícola colombiano demandada por los demás procesos.
Ahora bien, el modelo Uppsala (Johanson \& Vahlne, 1977) propone que el conocimiento que tienen las organizaciones acerca de los mercados internacionales tiende a incrementarse a medida que ingresan a más y nuevos mercados, y, al mismo tiempo, sugiere dos factores para la internacionalización: 1) la selección del país con menor distancia psicológica, es decir, menor diferencia en lenguaje, cultura, sistema político, nivel de educación y desarrollo industrial; y 2) el compromiso de mercado referido a los recursos que son requeridos para la inversión en el área de mercadeo. Según la evidencia analizada por Olevsky y Dunska (2014), este modelo es el de mayor impacto en los procesos de internacionalización de las mipymes asociadas con elementos agrícolas latinoamericanos.

Igualmente, Cardozo et al. (2013) explican las cuatro fases que facilitan el éxito de su aplicación, que incluyen, en primera instancia, la realización de actividades esporádicas u ocasionales de exportación, ya sea de manera directa o indirecta; segundo, la puesta en marcha de exportaciones a través de representantes independientes o comercializadores internacionales que poseen un mayor conocimiento del mercado internacional; tercero, el establecimiento de una sucursal en el país extranjero, generalmente el de destino, a través de licencias o franquicias; y cuarto, la instalación de unidades productivas en el extranjero (Cardozo et al., 2013). Cada una de las aplicaciones de este proceso 
muestra una aplicación sencilla y de fácil acceso a empresas pequeñas y medianas, que pueden ser implementadas en los procesos de comercialización de los productos agrícolas colombianos.

Por su parte, el modelo del ciclo de vida de Vernon (1979) considera la internacionalización como un proceso por etapas, que condiciona el desarrollo de nuevos productos según su ciclo de vida, teniendo en cuenta las economías de escala, la minimización de costos, los ingresos per cápita, la demanda y los activos empresariales. Su aplicación en economías avanzadas busca la introducción de nuevos productos para satisfacer las necesidades y deseos de los consumidores, con base en las ventajas productivas y de innovación (Cuervo-Cazurra, 2018). Por eso la relevancia de dar valor agregado a cada uno de los productos agrícolas disponibles, de manera que reflejen elementos que satisfagan las necesidades del consumidor, el mejoramiento de la calidad de los productos, la competitividad basada en la creación de nuevos aspectos asociados a su consumo y el análisis de tendencias que permita la permanencia en el mercado.

En Colombia, la producción agrícola y el seguimiento del sector diferencian dos componentes básicos. Flórez (2017, p. 78) los describe como "el asociado directamente con la producción campesina que incluye la cosecha, sostenimiento, recolección y tratamiento primario del producto y el sector industrial que abarca la transformación y generación de valor agregado". Este autor, al analizar la influencia de la cadena productiva en el mercado, lo define como una herramienta administrativa importante para la generación de valor agregado. De esta forma, cada una de las investigaciones y esfuerzos realizados por el Gobierno nacional y Asohofrucol, por el fortalecimiento de las cadenas productivas relacionadas con el agro colombiano, están mostrando resultados positivos como el aumento en la productividad de los cultivos, calculado entre un $25 \%$ y $30 \%$ de acuerdo con la zona, principalmente en plátano y banano, gracias a la adopción de nuevas tecnologías (Asohofrucol, 2015). Actualmente, y de acuerdo con las cifras del Ministerio de Agricultura y Desarrollo Rural (MADR), Colombia participa con el $8.6 \%$ de la producción mundial de plátano, y presenta un comportamiento estable, con una tasa de crecimiento anual promedio de $4.1 \%$, entre 2010 y 2013 (Ministerio de Agricultura y Desarrollo Rural [MADR], 2014). Sin embargo, según el mismo estudio, este producto ha venido perdiendo participación en el mercado internacional debido a la incursión de los productos provenientes de Ecuador y Honduras (2014), teniendo en cuenta que las principales limitaciones para la competitividad han estado representadas en las condiciones de infraestructura que afectan los costos de transporte y 
logística, los cuales aumentan los costos de operación y encarecen el precio final de los productos.

En este sentido, y teniendo en cuenta las condiciones de los modelos de internacionalización anteriormente expuestos, se hace necesaria la implementación de estrategias de expansión hacia nuevos mercados, adaptando sus principios a los contextos locales, particularidades y requerimientos de la cadena productiva que permitan una expansión global, sin dejar de lado los desafíos relacionados con las barreras internas y externas de los mercados a los cuales se dirige el producto. Barreras externas como el conocimiento de las actividades propias del comercio internacional, las diferencias culturales, los hábitos de consumo y el apoyo estatal, y las barreras internas como la identificación, selección y contactos con los mercados extranjeros, la escasez de recursos financieros y la inadecuada gestión de la información (Olevsky \& Dunska, 2014).

El cultivo de plátano en Colombia es considerado una actividad tradicional de la economía campesina con presencia geográfica significativa y de aporte socioeconómico relevante (MADR, 2014), de allí la importancia de la contribución al mejoramiento del sector productivo y transformador, con opciones de comercialización internacional de baja complejidad, que permita el acceso de pequeños productores.

\section{METODOLOGÍA}

Investigación mixta con alcance exploratorio, basada en un análisis documental de fuentes de información secundarias extraídas de reportes y estadísticas de producción a través de FAOSTAT, datos de importaciones y exportaciones relacionados en TRADEMAP y LEGISCOMEX, además de requisitos y documentación procesados mediante TRADEWIZARDS para el período 2013-2017. Se llevó a cabo en tres etapas: 1) identificación de mercados potenciales, 2) preselección y 3) selección de mercados, en donde se identifican las tendencias de consumo y las preferencias de alimentación con productos a base de plátano, así como el análisis del tamaño de mercado teniendo en cuenta variables como producción, importación y exportación del producto en fresco y procesado en el mundo, lo que permitió hallar los mercados con mayor volumen y dinámica comercial (Tabla1). Para la clasificación en cada una de ellas, fue considerado el concepto de distancia psicológica descrito por el modelo Uppsala (Johanson \& Vahlne, 1977) y las ventajas y restricciones propuestas por el modelo de ciclo de vida de producto de Vernon (Vernon, 1979). Se inicia entonces el proceso de aplicación metodológica teniendo en cuenta los países que presentan mayores niveles de consumo de plátano en fresco, así como también los productos procesados derivados del mismo que muestran mayor demanda, en donde se identifica 
una concentración de la demanda en las frituras o chips, plátano congelado y harina de plátano en 17 países. De allí se toman los datos iniciales de clasificación para la aplicación de cada una de las etapas propuestas.

El proceso de desarrollo y comercialización de productos requiere del análisis sectorial de los mercados de destino, con el fin de conocer y entender las necesidades y deseos de los consumidores, lo que implica la identificación de las oportunidades de mercado (Grunert, Verbeke, Kügler, Saeed \& Scholderer, 2011). Por ello, en la primera etapa se consideran las variables de tamaño de mercado, mercados destino, tendencias de consumo y perfil general de país.

Tabla 1. Descripción metodológica y etapas de la investigación

\begin{tabular}{|c|c|}
\hline Ítems & Descripción \\
\hline Alcance & $\begin{array}{l}17 \text { países, } \\
5 \text { años ( } 2013 \text { a } 2017) \text {. } \\
4 \text { productos (Plátano fresco, chips, plátano congelado, harina de plátano). }\end{array}$ \\
\hline Variables & Producción, Exportación, Importaciones, tendencias de consumo. \\
\hline Fuentes de datos & FAOSTAT, TRADEMAP y LEGISCOMEX, TRADEWIZARDS \\
\hline Instrumentos & Fichas documentales. \\
\hline \multirow[t]{2}{*}{$\begin{array}{l}\text { Etapa 1: Identificación } \\
\text { mercados potenciales. } \\
\text { Criterios }\end{array}$} & $\begin{array}{l}\text { Evaluación de } 17 \text { países: Panamá, Chile, Perú, México, Estados } \\
\text { Unidos, Canadá, Alemania, Bélgica, Francia, Reino Unido, Suiza, } \\
\text { Italia, Países Bajos, China, Japón, Tanzania y Nigeria. }\end{array}$ \\
\hline & $\begin{array}{l}\text { Tendencias alimenticias. } \\
\text { - Tamaño de mercado: Países con mayor cantidad de importaciones } \\
\text { - Mundiales de plátano fresco y productos procesados a base de plátano. } \\
\text { - de plátano en América Central y América del Sur. } \\
\text { - Consumo aparente de los países productores de plátano a nivel mundial. } \\
\text { - Trazabilidad de países importadores y exportadores de plátano. } \\
\text { - Perfil general de país: Condiciones macroeconómicas, } \\
\text { sociodemográficas y comerciales. }\end{array}$ \\
\hline \multirow{2}{*}{$\begin{array}{l}\text { Etapa 2: Preselección } \\
\text { de mercados } \\
\text { Criterios }\end{array}$} & $\begin{array}{l}\text { Evaluación cuantitativa de } 12 \text { países: Panamá, Chile, México, Estados Unidos, } \\
\text { Canadá, Alemania, Bélgica, Reino Unido, Suiza, Países Bajos, Japón. }\end{array}$ \\
\hline & $\begin{array}{l}\text { Condiciones de admisibilidad: } \\
\text { - } \quad \text { Barreras arancelarias: Aranceles, documentos de importación. } \\
\text { - } \text { Barreras No Arancelarias: Normas de etiquetado, permiso } \\
\text { para la comercialización, normatividad frente a registros, BPM, } \\
\text { trazabilidad, Requisitos para exportar e importar. } \\
\text { - Análisis Sectorial: Competencia, productos sustitutos, } \\
\text { empresas productoras, precios y productos. }\end{array}$ \\
\hline \multirow{2}{*}{$\begin{array}{l}\text { Etapa 3: Selección de } \\
\text { mercados } \\
\text { Criterios por País }\end{array}$} & 6 países: Estados Unidos, Suiza, México, Alemania, Países Bajos y Chile. \\
\hline & $\begin{array}{l}\text { - Distancia corta o media de Colombia con tiempos de tránsito máximo de } 30 \text { días. } \\
\text { - Alto PIB y Balanza comercial deficitaria en plátano. } \\
\text { - Mayor cantidad de Importaciones en productos a base de plátano. }\end{array}$ \\
\hline
\end{tabular}

Fuente: elaboración propia partir de combinación de parámetros del modelo Uppsala y ciclo de vida del producto de Vernon 
Las condiciones externas no controlables son determinantes en la selección de un país como mercado potencial, de allí que se adoptaran indicadores que afectan su inclusión o descarte de acuerdo con sus condiciones comerciales, sociodemográficas y macroeconómicas, tal como se muestra en la Figura 1. En la evaluación de los perfiles de país, se elaboró una matriz comparativa que permitiera calificar de 1 a 5 cada uno de los anteriores criterios, siendo 5 más favorable y 1 menos favorable para la comercialización de los productos a base de plátano.

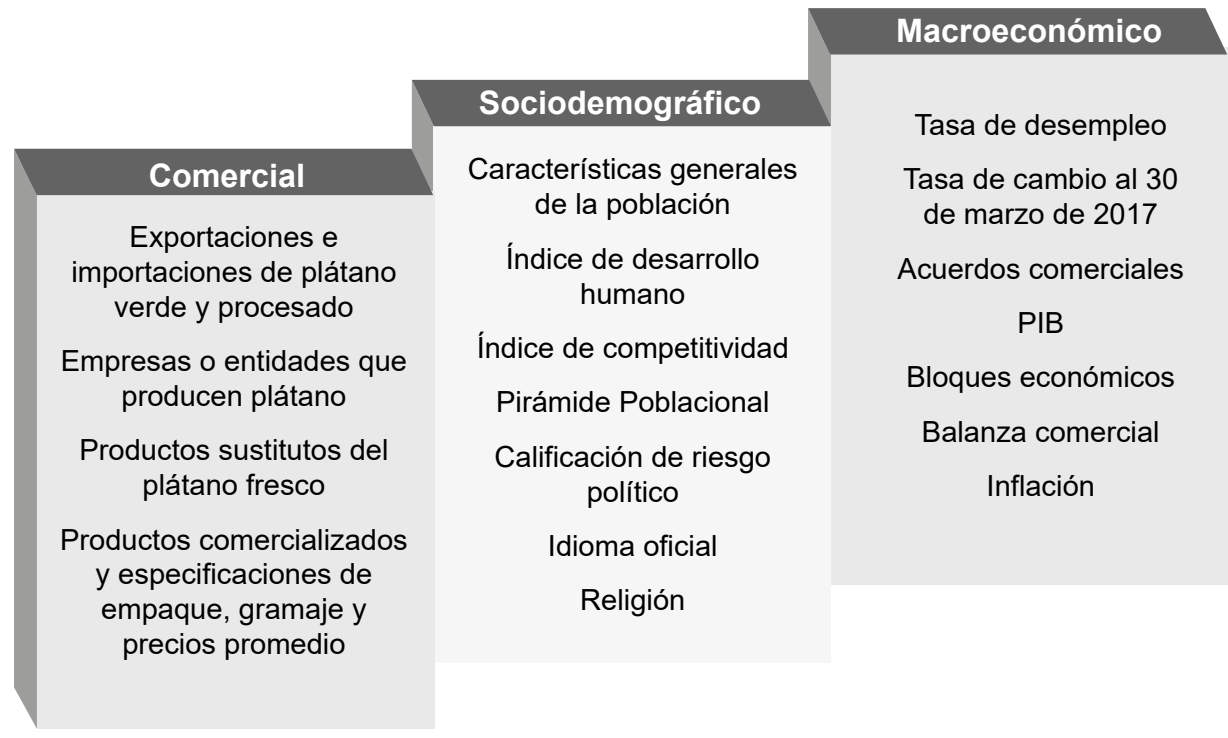

Figura 1. Criterios de selección para perfil general de país.

Para la segunda etapa, las condiciones de admisibilidad a mercados externos son determinantes al momento de su selección, por lo cual se incluyen en los procesos de búsqueda elementos como los acuerdos comerciales vigentes, aranceles, documentos de importación, requisitos para exportar e importar, permisos, registros y etiquetas para el plátano fresco y procesado. En la tercera etapa se priorizaron los países que mostraron mayores ventajas com- parativas considerando las variables de criterios logísticos, déficit de oferta y tendencias crecientes de consumo, tal como se ilustra en la Tabla 1.

\section{RESULTADOS}

Etapa 1. Identificación de mercados potenciales: los hallazgos relevantes en esta etapa tienen en cuenta las variables de tendencias alimenticias, tamaño del mercado y perfil general de los países. 


\section{Tendencias alimenticias}

En primera instancia se toman los resultados expuestos por Nielsen (2016) en su informe anual sobre tendencias de ingredientes y alimentación fuera del hogar, para realizar la clasificación de países que se muestra en la Tabla 2.

Tabla 2. Tendencias de ingredientes y alimentación

\begin{tabular}{|c|c|c|c|c|c|}
\hline \multirow[b]{2}{*}{ Ítems } & \multicolumn{5}{|c|}{ Porcentaje de encuestados por Nielsen (2016) } \\
\hline & $\begin{array}{l}\text { Norte } \\
\text { América }\end{array}$ & $\begin{array}{l}\text { América } \\
\text { Latina }\end{array}$ & Europa & $\begin{array}{l}\text { Asia- } \\
\text { Pacífico }\end{array}$ & África \\
\hline Alergia o intolerancia alimentaria & $31 \%$ & $34 \%$ & $22 \%$ & $42 \%$ & $50 \%$ \\
\hline \multicolumn{6}{|l|}{ Dieta Especial } \\
\hline Baja en grasa & $19 \%$ & $39 \%$ & $20 \%$ & $37 \%$ & $36 \%$ \\
\hline Baja en sodio & $21 \%$ & $24 \%$ & $8 \%$ & $22 \%$ & $13 \%$ \\
\hline Baja en Carbohidratos & $15 \%$ & $20 \%$ & $11 \%$ & $23 \%$ & $17 \%$ \\
\hline Vegetariana & $6 \%$ & $8 \%$ & $5 \%$ & $19 \%$ & $16 \%$ \\
\hline Sin trigo o sin gluten & $8 \%$ & $10 \%$ & $4 \%$ & $10 \%$ & $8 \%$ \\
\hline \multicolumn{6}{|l|}{ Ingredientes evitados } \\
\hline Conservantes artificiales & $53 \%$ & $54 \%$ & $61 \%$ & $67 \%$ & $62 \%$ \\
\hline Aromatizantes artificiales & $55 \%$ & $54 \%$ & $60 \%$ & $66 \%$ & $62 \%$ \\
\hline Colorante artificiales & & $56 \%$ & $60 \%$ & $65 \%$ & $62 \%$ \\
\hline OMG (Organismos genéticamente modificados) & & & $59 \%$ & & \\
\hline \multicolumn{6}{|l|}{ Búsqueda de la sencillez } \\
\hline Alimentos elaborados de forma & $76 \%$ & $81 \%$ & $77 \%$ & $78 \%$ & $77 \%$ \\
\hline casera son más sanos & $71 \%$ & $74 \%$ & $68 \%$ & $76 \%$ & $73 \%$ \\
\hline \multicolumn{6}{|l|}{$\begin{array}{l}\text { Mejor impresión hacia las empresas } \\
\text { transparentes con su trazabilidad en la cadena }\end{array}$} \\
\hline Necesidades dietéticas no están & & & & & \\
\hline completamente cubiertas & $41 \%$ & $63 \%$ & $51 \%$ & $56 \%$ & $63 \%$ \\
\hline
\end{tabular}

Fuente: elaboración propia a partir de datos publicados por Nielsen (2016)

Posteriormente se elabora la siguiente clasificación, teniendo en cuenta los resultados de los paneles de consumidores y trabajos de investigación aplicados en la industria alimentaria realizados por Alexander Kasriel en Euromonitor (2016), Innova Market Insight (2015) Mintel Group Ltd. (2017, 2018), de los cuales se obtienen los siguientes grupos según las tendencias analizadas:

1. Tradición: los consumidores buscan nuevos productos adaptados de fórmulas, sabores y formatos ancestrales, demandan productos más naturales y menos procesados que obligan a eliminar el uso de ingredientes artificiales.

2. Sostenibilidad y responsabilidad social: relaciona el origen de los productos, ingredientes, trazabilidad e historias inspiradoras con declaración de autenticidad; también tendencias de sostenibilidad y reducción de desperdicios en la industria 
alimentaria. Se destaca la nueva realidad eco, revelación total de datos, etiquetas limpias y claras que crean vínculos reales con pequeños jugadores, grandes ideas y elecciones conscientes o mindful choices.

3. Salud y bienestar: búsqueda de mejoramiento global de la salud física y mental, traducida en bienestar personal que incluye elementos como dietas especiales.

4. Experiencias: tendencias donde los alimentos son producto de placer que destacan los sabores, presentaciones y texturas que aportan a consumidores con un estilo de vida dinámico, aventurero y atrevido (Williams, 2017, p. 23).

5. Apropiación de tecnologías: revolución en la comercialización de los productos; las compras por internet y teléfonos móviles que se consolidan y brindan oportunidades para una nueva era de personalización que incluye promociones y productos dirigidos a públicos específicos. Se destaca el valor de la ciencia en la industria entendida como el aporte desde la tecnología.
Tamaño de mercado según producción, importaciones, exportaciones, mercados destino y perfil de país

De acuerdo con el análisis de las estadísticas disponibles de la Food and Agriculture Organization of the United Nations (FAO) para el rango de años del estudio 2013-2017 (2017), la producción mundial de plátano se reportó con 35 millones de toneladas en el período 2012 a 2016, mostrándose un incremento de 1.7 toneladas para el 2016. Sin embargo, solo el $15 \%$ de esta cantidad está destinada al comercio internacional, debido a la alta demanda del mercado interno de sus productores. Igualmente se encuentra que la participación por continente en la producción mundial se mantuvo de manera casi constante para el período 2012-2016, en el que África muestra una mayor participación con $56.7 \%$, Camerún fue el primer productor, con 4.3 millones de toneladas en 2016, seguido de Ghana y Uganda con 3.9 y 3.7 respectivamente; América con $29.5 \%$, en donde se destacan en América Latina las posiciones de Colombia, Perú y Ecuador, ubicados en la cuarta, sexta y decimocuarta posición en el ranking mundial en el mismo periodo. 


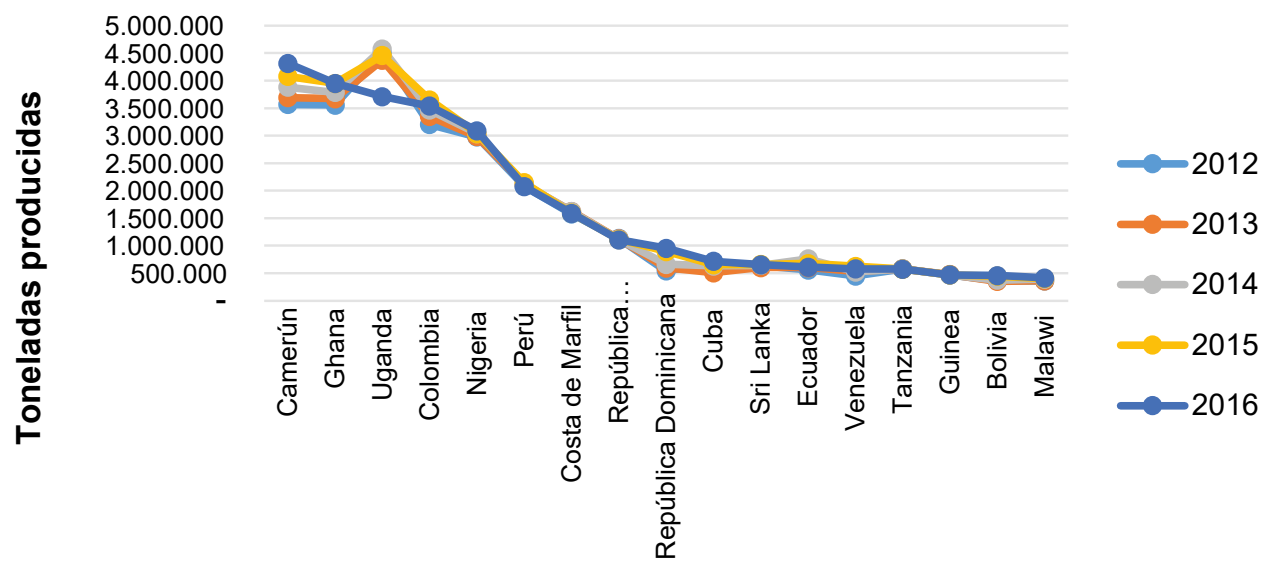

Figura 2. Producción mundial de plátano (2012-2016).

Fuente: elaboración propia a partir de datos de FAOSTAT - FAO (2017).

En cuanto a las exportaciones, fueron analizados el plátano en fresco y los productos procesados en chips, congelados y harina, por ser los de mayor demanda y comercialización. La siguiente tabla indica las posiciones arancelarias en las cuales fueron considerados.

Tabla 3. Clasificación arancelaria del plátano en fresco y producto procesado

\begin{tabular}{|c|c|c|}
\hline $\begin{array}{l}\text { Posición } \\
\text { Arancelaria }\end{array}$ & $\begin{array}{l}\text { Descripción } \\
\text { del producto }\end{array}$ & Descripción de la partida arancelaria \\
\hline 080310 & $\begin{array}{l}\text { Plátano fresco } \\
\text { o seco }\end{array}$ & Plátanos frescos o secos \\
\hline 200899 & $\begin{array}{l}\text { Chips de } \\
\text { plátano }\end{array}$ & $\begin{array}{l}\text { Frutas u otros frutos y demás partes comestibles de plantas, preparados } \\
\text { o conservados de otro modo, incluso con adición de azúcar u otro } \\
\text { edulcorante o alcohol, no expresados ni comprendidos en otra parte. }\end{array}$ \\
\hline 081190 & $\begin{array}{l}\text { Plátano } \\
\text { congelado }\end{array}$ & $\begin{array}{l}\text { Frutas y otros frutos, sin cocer o cocidos en agua o vapor, congelados, } \\
\text { incluso con adición de azúcar u otro edulcorante. }\end{array}$ \\
\hline 110630 & $\begin{array}{l}\text { Harina de } \\
\text { plátano }\end{array}$ & $\begin{array}{l}\text { Harina, sémola y polvo de los productos del capítulo } 8 \text { "frutos } \\
\text { comestibles; cortezas de agrios "cítricos", de melones o de sandías. }\end{array}$ \\
\hline
\end{tabular}

Fuente: datos Manual de Clasificación del Sistema Armonizado,

Organización Mundial de Aduanas (2016)

De acuerdo entonces con las posiciones arancelarias, es analizado el comportamiento de las exportaciones mundiales para el período 2013-2017, en el que los chips registraron la mayor participación y un crecimiento del $6 \%$ en su volumen y un $9 \%$ en su valor. En el 2017, China fue el país destacado con mayor nivel de exportación, reportando un $32.3 \%$, seguido de Estados Unidos con $6.8 \%$. 
Por su parte, Colombia se ubicó en la posición 15 con una participación de $1.6 \%$ en las exportaciones de chips.

Tabla 4. Exportaciones mundiales de plátano en fresco y producto procesado (volumen y valor en miles de dólares)

\begin{tabular}{ccccccccccc}
\hline $\begin{array}{c}\text { Descripción } \\
\text { producto }\end{array}$ & \multicolumn{4}{c}{ Volumen MTn } & \multicolumn{5}{c}{ Valor miles US } \\
\cline { 2 - 12 } & 2013 & 2014 & 2015 & 2016 & 2017 & 2013 & 2014 & 2015 & 2016 & 2017 \\
\hline $\begin{array}{c}\text { Plátano } \\
\text { Fresco }\end{array}$ & 961 & 889 & 1.112 & 1.165 & 1.278 & 493 & 488 & 578 & 643 & 686 \\
\hline $\begin{array}{c}\text { Chips de } \\
\text { Plátano }\end{array}$ & 1.335 & 1.379 & 1.466 & 1.553 & 1.630 & 2.744 & 2.973 & 2.865 & 2.944 & 3.342 \\
\hline $\begin{array}{c}\text { Plátano } \\
\text { Congelado }\end{array}$ & 1.022 & 1.082 & 1.193 & 1.195 & 1.272 & 2.220 & 2.283 & 2.305 & 2.279 & 2.447 \\
\hline $\begin{array}{c}\text { Harina de } \\
\text { Plátano }\end{array}$ & 100 & 98 & 119 & 96 & 89 & 293 & 309 & 355 & 350 & 342 \\
\hline
\end{tabular}

Fuente: elaboración propia a partir de datos de Trademap (2018)

El plátano congelado fue el segundo producto de los seleccionados, con mayores niveles de exportación mundial durante 2013-2017. Representó un crecimiento del $6 \%$ en volumen y del $2 \%$ en valor. Durante el 2017, Canadá fue el país que registró la mayor exportación mundial con un $10.4 \%$, mientras que Colombia ocupó el lugar 48 con una participación de $0.1 \%$. Por su parte, las exportaciones de plátano fresco crecieron un $80 \%$ en volumen, en contraste con el $1 \%$ en valor, durante el periodo analizado. República Dominicana fue el principal país exportador en el año 2017 con un $17.2 \%$, seguido de Guatemala con un $12.7 \%$, mientras que Colombia se ubicó en la quinta posición con una participación de $8.8 \%$.

Tabla 5. Exportaciones mundiales de plátano en fresco y producto procesado según país de origen

\begin{tabular}{|c|c|c|c|c|}
\hline \multirow{2}{*}{$\begin{array}{l}\text { Posición } \\
\text { arancelaria }\end{array}$} & \multirow[b]{2}{*}{ Producto } & \multicolumn{3}{|c|}{ Exportaciones 2017} \\
\hline & & País de origen & $\begin{array}{c}\text { Valor } \\
\text { (miles de USD) }\end{array}$ & $\begin{array}{l}\text { Volumen } \\
\text { (t) }\end{array}$ \\
\hline \multirow[t]{5}{*}{080310} & Plátano fresco y seco & República Dominicana & 118.095 & 143.744 \\
\hline & & Guatemala & 87.466 & 236.571 \\
\hline & & Ecuador & 85.730 & 158.991 \\
\hline & & Filipinas & 79.541 & 251.792 \\
\hline & & Colombia & 60.809 & 117.797 \\
\hline \multirow[t]{5}{*}{200899} & Chips de plátano & China & 1.394 .038 & 358.615 \\
\hline & & Estados Unidos & 293.340 & 63.656 \\
\hline & & Países Bajos & 251.421 & 146.603 \\
\hline & & México & 244.608 & 110.538 \\
\hline & & Tailandia & 176.634 & 102.006 \\
\hline
\end{tabular}


Continuación Tabla 5

\begin{tabular}{|c|c|c|c|c|}
\hline \multirow[t]{5}{*}{081190} & \multirow[t]{5}{*}{ Plátano congelado } & Canadá & 253.453 & 141.209 \\
\hline & & Polonia & 173.555 & 105.505 \\
\hline & & Chile & 166.532 & 60.868 \\
\hline & & Estados Unidos & 159.253 & 78.174 \\
\hline & & Países Bajos & 133.993 & 69.935 \\
\hline \multirow[t]{5}{*}{110630} & \multirow[t]{5}{*}{ Harina de plátano } & España & 74.091 & 12.337 \\
\hline & & Estados Unidos & 31.466 & 17.386 \\
\hline & & Turquía & 27.492 & 4.578 \\
\hline & & Alemania & 21.447 & 2.041 \\
\hline & & Malasia & 21.224 & 4.670 \\
\hline
\end{tabular}

Fuente: elaboración propia a partir de datos de Trademap (2018)

Finalmente, las exportaciones de harina de plátano durante el mismo periodo aumentaron en un $5 \%$ en millones de dólares y presentaron una disminución en volumen del $2 \%$. Durante el 2017, España fue el principal exportador con una participación del $21.7 \%$, seguido de Estados Unidos con 9.2 \%; Colombia no registró exportaciones de este producto.

En las estadísticas de importación, los chips fueron también los más representativos tanto en volumen como en millones de dólares, con un crecimiento de 10 $\%$ y $5 \%$, respectivamente. En el 2017, Estados Unidos fue el principal país con una participación de $31.7 \%$, seguido de Japón con $8.8 \%$. Colombia se ubicó en la posición 50 con una participación de $0.1 \%$.

El plátano congelado fue el segundo producto con mayor volumen de importación durante el período 2013-2017, mostrando un crecimiento de $1 \%$ en dólares pero una disminución del $2 \%$ en volumen. En el año 2017, Estados Unidos fue el país con la mayor importación de este producto con una participación de $17.1 \%$, seguido de Alemania con $11.2 \%$. Colombia ocupó el lugar 68 con una participación de $0.1 \%$.

Tabla 6. Importaciones mundiales de plátano en fresco y procesado

\begin{tabular}{cccccccccccc}
\hline Descripción & \multicolumn{4}{c}{ Volumen MTn } & \multicolumn{5}{c}{ Valor MTn } \\
\cline { 2 - 13 } producto & 2013 & 2014 & 2015 & 2016 & 2017 & 2013 & 2014 & 2015 & 2016 & 2017 \\
\hline Plátano fresco & 1.579 & 1.676 & 1.388 & 2.029 & 1.310 & 1.102 & 1.122 & 833 & 1.358 & 805 \\
\hline Chips de plátano & 1.609 & 1.708 & 1.751 & 1.820 & 1.906 & 2.977 & 3.162 & 3.212 & 3.398 & 3.842 \\
\hline Plátano congelado & 1.094 & 1.123 & 1.234 & 1.272 & 1.311 & 2.465 & 2.472 & 2.496 & 2.494 & 2.565 \\
\hline Harina de plátano & 80 & 81 & 81 & 88 & 86 & 256 & 299 & 337 & 341 & 330 \\
\hline
\end{tabular}

Fuente: elaboración propia a partir de datos de Trademap (2018) 
Por otra parte, el plátano fresco y seco fue uno de los productos con menor importación, con un crecimiento en valor y volumen del $5 \%$ y $8 \%$ respectivamente. Estados Unidos con una par- ticipación de $28.3 \%$ fue el país con la mayor importación, seguido de Arabia Saudita con $15.3 \%$. Colombia no registró importaciones de estas subpartidas.

Tabla 7. Importaciones mundiales de plátano en fresco y procesado según países importadores

\begin{tabular}{|c|c|c|c|c|}
\hline \multirow[b]{2}{*}{$\begin{array}{c}\text { Posición } \\
\text { arancelaria }\end{array}$} & \multirow[b]{2}{*}{ Producto } & \multirow[b]{2}{*}{ Países importadores } & \multicolumn{2}{|c|}{ Importaciones 2017} \\
\hline & & & $\begin{array}{c}\text { Valor } \\
\text { (Miles de USD) }\end{array}$ & $\begin{array}{c}\text { Volumen } \\
(\mathrm{t})\end{array}$ \\
\hline \multirow{5}{*}{080310} & \multirow{5}{*}{ Plátano Fresco y seco } & Estados Unidos & 227.963 & 381.682 \\
\hline & & Arabia Saudita & 122.849 & 193.603 \\
\hline & & Países Bajos & 75.476 & 73.568 \\
\hline & & Rumania & 53.803 & 70.586 \\
\hline & & Reino Unido & 42.697 & 73.671 \\
\hline \multirow{5}{*}{200899} & \multirow{5}{*}{ Chips de plátano } & Estados Unidos & 1.470 .108 & 592.186 \\
\hline & & Japón & 408.862 & 96.967 \\
\hline & & Países Bajos & 284.879 & 208.008 \\
\hline & & China & 260.275 & 58.603 \\
\hline & & Francia & 240.947 & 107.244 \\
\hline \multirow{5}{*}{081190} & \multirow{5}{*}{ Plátano congelado } & Estados Unidos & 437.447 & 226.891 \\
\hline & & Alemania & 287.584 & 192.926 \\
\hline & & Francia & 175.071 & 86.548 \\
\hline & & Países Bajos & 135.391 & 84.960 \\
\hline & & China & 129.981 & 36.037 \\
\hline \multirow{5}{*}{110630} & \multirow{5}{*}{ Harina de plátano } & Francia & 45.376 & 6.932 \\
\hline & & República de Corea & 36.834 & 2.831 \\
\hline & & Alemania & 30.118 & 5.860 \\
\hline & & Estados Unidos & 16.333 & 4.160 \\
\hline & & Canadá & 13.405 & 1.860 \\
\hline
\end{tabular}

Fuente: elaboración propia a partir de datos de Trademap (2018)

La harina de plátano fue el producto con menor importación y presentó una disminución de $4 \%$ en volumen, mientras que aumentó en millones de dólares un $7 \%$ durante el mismo período. En el 2017, el país con la mayor importación fue Francia con un $13.8 \%$, seguido de República de Corea con $11.2 \%$. Colombia ocupó la posición 74 con una parti- cipación de $0.1 \%$ en las importaciones mundiales.

En el 2017, los países con mayor producción de plátano de América Latina (Colombia, Perú, Ecuador y Guatemala), exportaron sus productos a base de plátano principalmente al mercado estadounidense. El producto con mayor representatividad fue el plátano fresco 
y seco con un volumen de 64.675 t y un valor de 30.436 millones de dólares.

El consumo aparente para los países productores fue calculado como la diferencia entre la producción nacional y la relación entre las importaciones y exportaciones expresada en la Figura 3. De acuerdo con la dinámica de la producción y la balanza comercial, se infiere que aquellos países con consumo aparente de plátano negativo como Ecuador, Guatemala y República Dominicana, no representan un potencial de exportación para Colombia, debido a que son los principales exportadores de este producto a los mercados internacionales y su producción satisface su demanda interna.

6.000

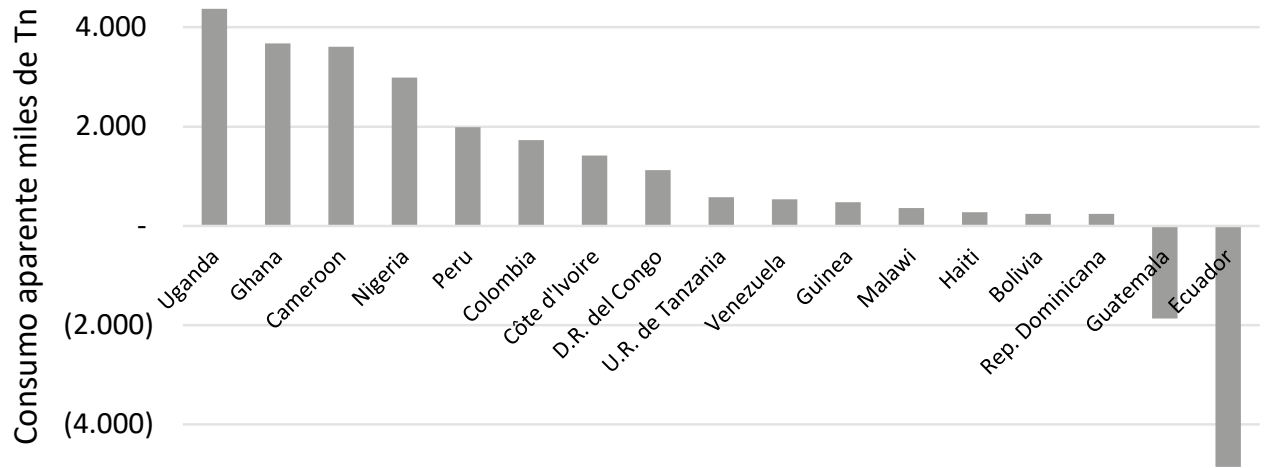

(6.000)

Figura 3. Consumo aparente de países productores de plátano.

Fuente: elaboración propia a partir de datos de FAOSTAT y Trademap (2018)

Al analizar la trazabilidad se identifica que el principal importador mundial que actúa como distribuidor del producto hacia otros destinos es Estados Unidos, cuyos principales mercados de exportación son Canadá, México y Corea del Sur; seguido por Bélgica, Italia, Alemania, los cuales, a su vez, exportan hacia otros países europeos como Francia, Austria y Países Bajos. 
Tabla 8. Trazabilidad de países importadores y distribuidores de plátano

\begin{tabular}{|c|c|c|}
\hline \multicolumn{3}{|c|}{ Países importadores y exportadores } \\
\hline Producto & & \\
\hline \multirow[t]{5}{*}{ Plátano fresco y seco } & Estados Unidos & Italia \\
\hline & Bélgica & Hungría \\
\hline & Reino Unido & Sudáfrica \\
\hline & Países Bajos & \\
\hline & España & \\
\hline \multirow[t]{5}{*}{ Chips de plátano } & Estados Unidos & Francia \\
\hline & México & Bélgica \\
\hline & Canadá & España \\
\hline & Países Bajos & Polonia \\
\hline & Alemania & China \\
\hline \multirow[t]{5}{*}{ Harina de plátano } & Estados Unidos & Bélgica \\
\hline & Alemania & Taipei Chino \\
\hline & Italia & Malasia \\
\hline & Reino Unido & China \\
\hline & Irlanda & \\
\hline \multirow[t]{5}{*}{ Plátano congelado } & Estados Unidos & Países Bajos \\
\hline & Canadá & Bélgica \\
\hline & Chile & Polonia \\
\hline & Alemania & Bielorrusia \\
\hline & Italia & China \\
\hline
\end{tabular}

Fuente: elaboración propia a partir de datos de Trademap (2018)

Igualmente, los países asiáticos, como Japón y Rusia, hacen parte de los mercados a los que se exportan la harina y los chips de plátano desde Ecuador y Perú, elemento que se ratifica en las cifras de consumo de plátano de los últimos cinco años, puesto que en la Unión Europea el consumo alcanzó los $11.2 \mathrm{~kg}$ per cápita durante el 2014, superando así el consumo en 2012 y 2013 de 900 g y $600 \mathrm{~g}$ respectivamente.

El mercado europeo se consolida como el primer consumidor de plátano en el mundo, con 5.7 millones de toneladas, destacándose como principales consumidores Reino Unido y Suecia, con más de $14 \mathrm{~kg}$ per cápita. Del mismo modo, Estados Unidos es el segundo mercado con este comportamiento, con un consumo neto de 4 millones de toneladas en el 2014 y un consumo per cápita de 12.5 $\mathrm{kg}$, que se ha mantenido estable en el tiempo, de acuerdo con United Nations Conference on Trade and Development (UNCTAD, 2016, p. 7).

En contraste, el consumo de plátano en el mercado ruso presentó un crecimiento estable desde el año 2000, llegando a más de $9 \mathrm{~kg}$ per cápita durante el 2013, a causa del desarrollo de las importaciones de los operadores que se establecieron en Ecuador. Sin embargo, 
la depreciación del rublo frente al dólar estadounidense, impulsada por una caída en los precios de la energía, debido a la inflación interna y las sanciones impuestas por Europa y Estados Unidos por el conflicto con Ucrania, el precio de los productos importados como el plátano aumentó significativamente, reduciendo el consumo a $8.6 \mathrm{~kg}$ per cápita en el 2014. Situación similar ocurre con Japón, cuyo consumo de plátano y banano ha estado disminuyendo desde 2009 por la caída de sus importaciones, lo que ha causado una reducción en el consumo anual per cápita a $7.4 \mathrm{~kg}$ debido a la devaluación del yen, que favorece las exportaciones en lugar de las importaciones, y a la disminución del consumo de los hogares ocasionada por el gran aumento del IVA (UNCTAD, 2016).

Por otra parte, el análisis de la balanza comercial permitió identificar 17 mercados con alto volumen de comercio, razón por la cual se consideran con potencial para la exportación desde Colombia. Después de seleccionados estos 17 países, se procedió a aplicar el perfil general del país, como último criterio de la primera etapa, basado en el modelo de internacionalización de Uppsala. Los resultados de los criterios a los indicadores macroeconómicos y sociodemográficos fueron calificados de 1 a 5 , con el fin de totalizar el puntaje y eliminar los cinco países con menor potencial (Tabla 9).

Tabla 9. Resultados generales de los factores macroeconómicos y sociodemográficos

\begin{tabular}{|c|c|c|c|c|c|}
\hline \multicolumn{3}{|c|}{ Macroeconómico } & \multicolumn{3}{|c|}{ Sociodemográfico } \\
\hline Variable & Valoración & Mercado potencial & Variable & Valoración & Mercado potencial \\
\hline $\begin{array}{c}\text { Tasa de } \\
\text { desempleo }\end{array}$ & $\begin{array}{c}\text { Tasa de } \\
\text { desempleo más } \\
\text { baja } 2017\end{array}$ & $\begin{array}{l}\text { Suiza }(3.4 \%) \\
\text { Japón }(3.2 \%)\end{array}$ & $\begin{array}{c}\text { Características } \\
\text { generales de la } \\
\text { población }\end{array}$ & $\begin{array}{l}\text { Alta cantidad de } \\
\text { inmigrantes de } \\
\text { origen latino }\end{array}$ & $\begin{array}{l}\text { Chile, México y } \\
\text { Estados Unidos }\end{array}$ \\
\hline $\begin{array}{l}\text { Tasa de } \\
\text { cambio }\end{array}$ & $\begin{array}{c}\text { Tasa de cambio } \\
\text { al } 30 \text { de marzo de } \\
2017\end{array}$ & $\begin{array}{l}\text { Chile: } 0,0015 \\
\text { Japón: } 0,0089\end{array}$ & $\begin{array}{l}\text { Índice de } \\
\text { desarrollo } \\
\text { humano }\end{array}$ & $\begin{array}{l}\text { Mayor puntaje } \\
\text { obtenido de } \\
\text { acuerdo al IDH } \\
2016\end{array}$ & $\begin{array}{c}\text { USA }(0,92), \\
\text { Canadá }(0,92) \\
\text { Suiza }(0,93) \\
\text { Alemania }(0,926)\end{array}$ \\
\hline $\begin{array}{l}\text { Acuerdos } \\
\text { comerciales }\end{array}$ & $\begin{array}{l}\text { Acuerdos } \\
\text { comerciales } \\
\text { y TLC con } \\
\text { Colombia }\end{array}$ & $\begin{array}{l}\text { Estados Unidos y } \\
\text { Europa, Alianza } \\
\text { Pacífico } \\
\text { (Perú, México, Chile) }\end{array}$ & $\begin{array}{c}\text { Índice de } \\
\text { competitividad }\end{array}$ & $\begin{array}{c}\text { Mayor puntaje } \\
\text { en reporte de } \\
\text { competitividad } \\
\text { global 2016-2017. }\end{array}$ & $\begin{array}{c}\text { USA }(5,70) \\
\text { Alemania }(5,57) \\
\text { Suiza }(5,81) \\
\text { Países Bajos } \\
(5,57)\end{array}$ \\
\hline $\begin{array}{l}\text { Producto } \\
\text { Interno } \\
\text { bruto }\end{array}$ & $\begin{array}{l}\text { Mayor PIB del } \\
\text { año } 2016\end{array}$ & $\begin{array}{c}\text { Estados Unidos } \\
\text { (MM USD } \\
\text { 18.569.100), }\end{array}$ & $\begin{array}{c}\text { Pirámide } \\
\text { poblacional }\end{array}$ & $\begin{array}{l}\text { Mayor población } \\
\text { entre } 20 \text { y } 35 \\
\text { años. }\end{array}$ & $\begin{array}{l}\text { Chile, Suiza e } \\
\text { Italia }\end{array}$ \\
\hline
\end{tabular}




\section{Continuación Tabla 9}

\begin{tabular}{|c|c|c|c|c|c|}
\hline \multicolumn{3}{|c|}{ Macroeconómico } & \multicolumn{3}{|c|}{ Sociodemográfico } \\
\hline Variable & Valoración & Mercado potencial & Variable & Valoración & Mercado potencial \\
\hline $\begin{array}{c}\text { Bloques } \\
\text { económicos }\end{array}$ & $\begin{array}{l}\text { Pertenencia } \\
\text { y asociación } \\
\text { con bloques } \\
\text { económicos } \\
\text { mundiales }\end{array}$ & $\begin{array}{c}\text { Alianza Pacífico: } \\
\text { Chile, Perú y México. }\end{array}$ & $\begin{array}{l}\text { Calificación de } \\
\text { riesgo político }\end{array}$ & $\begin{array}{l}\text { Riesgo bajo(2) } \\
\text { de acuerdo con } \\
\text { la calificación de } \\
\text { riesgo político } \\
\text { y terrorismo de } \\
\text { AON. }\end{array}$ & $\begin{array}{c}\text { Panamá, Canadá, } \\
\text { y Suiza }\end{array}$ \\
\hline $\begin{array}{l}\text { Balanza } \\
\text { comercial }\end{array}$ & $\begin{array}{l}\text { Balanza } \\
\text { comercial } \\
\text { deficitaria }\end{array}$ & $\begin{array}{c}\text { Estados Unidos } \\
\text { (-796.744,5 MMUSD) } \\
\text { Francia } \\
\text { (-71.759,0 MMUSD) } \\
\text { Reino Unido } \\
\text { (-226.365,6 MMUSD) }\end{array}$ & Idioma Oficial & $\begin{array}{l}\text { Países de habla } \\
\text { hispana o inglesa }\end{array}$ & $\begin{array}{c}\text { Panamá, Chile, } \\
\text { Perú, México, } \\
\text { Estados Unidos, } \\
\text { Canadá, Reino } \\
\text { Unido }\end{array}$ \\
\hline $\begin{array}{l}\text { Inflación } \\
(2016)\end{array}$ & $\begin{array}{c}\text { Menor tasa de } \\
\text { inflación para el } \\
\text { año } 2016\end{array}$ & $\begin{array}{c}\text { Suiza }(-0,4 \%) \\
\text { Italia }(-0,2 \%) \\
\text { Japón }(-0,1 \%)\end{array}$ & & & \\
\hline
\end{tabular}

Fuente: elaboración propia a partir de datos de Trademap (2018) y calificación de resultados

Etapa 2. Preselección de mercados: al aplicar los criterios de la etapa 1, se descartaron China, Italia, Nigeria, Perú y Tanzania, ya que obtuvieron una calificación inferior a 50 puntos. A los países restantes se aplicaron los criterios de admisibilidad y análisis sectorial, expuestos en la Tabla 1.

Para analizar las condiciones de admisibilidad, se tienen en cuenta los tipos de barreras de entrada comerciales que incluyen las arancelarias y no arancelarias señaladas por Berden, Francois, Thelle, Wymenga y Tamminen (2009) (2013). Para ello se realiza búsqueda a través de la base de datos Tradewizards, así como las instituciones de agricultura oficiales de cada país, en donde se identificaron barreras de entrada tales como registros y certificaciones de Buenas Prácticas de Manufactura (BPM) y sanitarias. Cabe resaltar que Estados Unidos y los países pertenecientes a la Unión Europea son los que registran mayores requisitos relacionados con las normas de etiquetado que exigen declarar los valores nutricionales, aditivos, colorantes y posibles contaminantes o amenazas biológicas.

Colombia, por su parte, cuenta con preferencias arancelarias en los 12 países potenciales, gracias a los acuerdos comerciales y a los bloques económicos a los cuales pertenece. Sin embargo, deben tenerse en cuenta impuestos como el impuesto al valor agregado (IVA) con tasas diferenciales por país. 
Tabla 10. Descripción de requisitos generales de importación de plátano en fresco y procesado

\begin{tabular}{|c|c|}
\hline Indicador & Requisitos \\
\hline Arancel & Preferencias arancelarias por TLC o acuerdos con Colombia \\
\hline $\begin{array}{l}\text { Documentos de } \\
\text { importación }\end{array}$ & $\begin{array}{l}\text { Documentos universales: guía de carga, factura comercial, confirmación del } \\
\text { seguro, lista de empaque, factura proforma, carta de navegación marítima } \\
\text { autoridades colombianas: poder legal, declaración de exportación } \\
\text { importador: manifiesto de entrada de mercancía, declaración de carga interna, } \\
\text { declaración sumaria de entrada, entrada / entrega inmediata. } \\
\text { Documentos importación de productos: solicitud de permiso de importación, } \\
\text { solicitud de permiso de tránsito, formulario de declaración, notificación electrónica } \\
\text { previa de alimentos. }\end{array}$ \\
\hline Normas de etiquetado & $\begin{array}{l}\text { La Ley sobre Etiquetado de Productos Nutritivos y Educación exige que la } \\
\text { mayoría de los alimentos incluyan un etiquetado de información nutricional, y } \\
\text { que las etiquetas de alimentos que contienen afirmaciones sobre el contenido } \\
\text { de nutrientes y determinados mensajes sobre salud cumplan con requisitos } \\
\text { específicos. } \\
\text { Los productos procesados deben cumplir la Ley de Etiquetado Alérgeno de } \\
\text { Alimento y Protección al Consumidor. } \\
\text {-Afirmaciones y declaraciones sobre salud, sugerencias alimenticias deben ir } \\
\text { soportadas por estudios y datos nutricionales y serán revisadas por la FDA. }\end{array}$ \\
\hline $\begin{array}{l}\text { Permiso para la } \\
\text { comercialización }\end{array}$ & Notificación previa o autorización de importación \\
\hline $\begin{array}{l}\text { Normatividad frente } \\
\text { a registros, BPM, } \\
\text { trazabilidad }\end{array}$ & $\begin{array}{l}\text { Registro de instalaciones de alimentos. } \\
\text { Alimentos enlatados con bajo contenido de ácido / Alimentos acidificados } \\
\text { BPM }\end{array}$ \\
\hline
\end{tabular}

Fuente: elaboración propia a partir de datos de Trade Wizards (2018)

Mediante la revisión de tiendas en línea en el mundo, se hizo inteligencia de mercados para identificar marcas, productos, presentaciones y precios en los países objeto de análisis, en los cuales, además de los criterios aplicados en la Tabla 3, se identificaron diferentes productos procesados, refrigerados, congelados, precocidos y horneados, comercializados de manera especial en países latinoamericanos y Estados Unidos. La Tabla 11 consolida los hallazgos donde se identifican diferentes productos elaborados a base de plátano.

Tabla 11. Descripción de productos y marcas líderes en mercados potenciales

\begin{tabular}{|c|c|c|c|c|c|}
\hline País & Producto & Marca & $\begin{array}{l}\text { Precio } \\
\text { USD }\end{array}$ & Gramaje & $\begin{array}{c}\text { Tiendas online } \\
\text { consultadas }\end{array}$ \\
\hline Panamá & $\begin{array}{c}\text { Patacones prefritos } \\
\text { Crema de plátano } \\
\text { Harina de plátano } \\
\text { Chips de plátano (sabor sal y } \\
\text { limón) } \\
\text { Plátano fresco verde } \\
\text { Plátano maduro }\end{array}$ & $\begin{array}{c}\text { Rimith } \\
\text { Ricacrema } \\
\text { Jagasa } \\
\text { Prosnacks }\end{array}$ & $\begin{array}{l}4,96 \\
2,49 \\
0,51 \\
0,88 \\
1,32 \\
1,58\end{array}$ & $\begin{array}{l}400 \mathrm{~g} \\
300 \mathrm{~g} \\
90 \mathrm{~g} \\
90 \mathrm{~g} \\
1000 \mathrm{~g} \\
1000 \mathrm{~g}\end{array}$ & $\begin{array}{c}\text { Riba Smith } \\
\text { Supermercados }\end{array}$ \\
\hline
\end{tabular}


Continuación Tabla 11

\begin{tabular}{|c|c|c|c|c|c|}
\hline Chile & $\begin{array}{l}\text { Yogurt batido de plátano } \\
\text { Plátano liofilizado } \\
\text { Chips de plátano } \\
\text { Plátano fresco Barraganete }\end{array}$ & $\begin{array}{l}\text { Soprole } \\
\text { So Natural } \\
\text { Samai }\end{array}$ & $\begin{array}{l}0,29 \\
1,54 \\
0,60 \\
1,79\end{array}$ & $\begin{array}{l}120 \mathrm{~g} \\
20 \mathrm{~g} \\
142 \mathrm{~g} \\
1000 \mathrm{~g}\end{array}$ & $\begin{array}{l}\text { Jumbo } \\
\text { Lider }\end{array}$ \\
\hline \multirow[t]{5}{*}{ Perú } & Compota de plátano & Gloria & 0,89 & $113 g$ & Wong, Cencosud \\
\hline & Yogurt de plátano & Tigo & 1,29 & $160 \mathrm{~g}$ & Plaza vea \\
\hline & Chiffles (chips) & Gelce & 0,52 & $40 \mathrm{~g}$ & \\
\hline & Plátano fresco Seda & & 0,61 & $1000 \mathrm{~g}$ & \\
\hline & Plátano fresco Bellaco & & 1,68 & $1000 \mathrm{~g}$ & \\
\hline \multirow[t]{5}{*}{ México } & Chips de plátano & Charricos & 0,80 & $50 \mathrm{~g}$ & HEB \\
\hline & Plátaos deshidratados & Turbana & 7,72 & $1000 \mathrm{~g}$ & Superama \\
\hline & Muffin de plátano & Only light & 1,11 & $100 \mathrm{~g}$ & \\
\hline & Plátano Dominico & & 1,50 & $1000 \mathrm{~g}$ & \\
\hline & Plátano Macho & & 1,18 & $1000 \mathrm{~g}$ & \\
\hline \multirow[t]{4}{*}{ Canadá } & Chips de plátano dulces & Grace & 1,27 & $85 \mathrm{~g}$ & Walmart \\
\hline & Chips de plátano picante & Inka & 3,77 & $113 g$ & IGA \\
\hline & Compota de banano & Buddy Fruits & 1,66 & $90 \mathrm{~g}$ & \\
\hline & Plátano fresco & & 0,32 & $1000 \mathrm{~g}$ & \\
\hline Estados & Chips de plátano orgánico & Platayuc & 2,99 & $8,5 \mathrm{~g}$ & Walmart \\
\hline \multirow[t]{8}{*}{ Unidos } & Banano deshidratado & Just Fresh Direct & 3,29 & $226,8 \mathrm{~g}$ & Fresdirect \\
\hline & Banano congelado cubierto con & Diana's Bananas & 4,99 & $595 \mathrm{~g}$ & \\
\hline & chocolate & Goya & 2,89 & $454 \mathrm{~g}$ & \\
\hline & Tostones & Goya & 2,48 & $298 \mathrm{~g}$ & \\
\hline & Mangú & Chiffles & 15,98 & $85 g$ & \\
\hline & Sopa de plátanos & & 0,99 & $1000 \mathrm{~g}$ & \\
\hline & Plátano verde & & 1,49 & $1000 \mathrm{~g}$ & \\
\hline & Plátano maduro & & & & \\
\hline \multirow[t]{4}{*}{ Alemania } & Banano cubierto de chocolate & Napoli & 1,95 & $300 \mathrm{~g}$ & Kaufland \\
\hline & Néctar de banano & K-classic & 0,98 & $1 \mathrm{~L}$ & \\
\hline & Chips de plátano & Tropical Gourmet & 1,35 & $85 \mathrm{~g}$ & \\
\hline & Plátano fresco & & 4,38 & $1000 \mathrm{~g}$ & \\
\hline \multirow[t]{5}{*}{ Suiza } & Banano Deshidratado & Seeberger & 2,81 & $150 \mathrm{~g}$ & Coop@home \\
\hline & Chips de plátano salado & Haldirams & 2,51 & $200 \mathrm{~g}$ & Desimarkt \\
\hline & Yogurt de banano orgánico & Naturaplan & 0,75 & $180 \mathrm{~g}$ & \\
\hline & Banano cubierto de chocolate & Kras & 0,35 & $30 \mathrm{~g}$ & \\
\hline & Plátano fresco & & 4,00 & $1000 \mathrm{~g}$ & \\
\hline Países & Chips de plátano & Haldirams & 2,77 & $200 \mathrm{~g}$ & Hollandathome \\
\hline \multirow[t]{4}{*}{ Bajos } & Postre de banano & Dr.Oetker & 4,90 & $125 \mathrm{~g}$ & Ekirana \\
\hline & Chips de banano & Bountiful & 3,23 & $200 \mathrm{~g}$ & \\
\hline & Nectar de banano & $\mathrm{AH}$ & 1,79 & $1 \mathrm{~L}$ & \\
\hline & Plátano fresco & & 3,31 & $1000 \mathrm{~g}$ & \\
\hline \multirow[t]{4}{*}{ Bélgica } & Chips de plátano & Fyffes & 0,91 & $70 \mathrm{~g}$ & Cirkle \\
\hline & Chips de banano & Kamlesh & 2,94 & $180 \mathrm{~g}$ & Carrefour Drive \\
\hline & Licor de Banano & Pisang Ambon & 2,29 & $0,7 \mathrm{~L}$ & \\
\hline & Soya de Banano & Alpro & & $250 \mathrm{ml}$ & \\
\hline
\end{tabular}

Fuente: elaboración propia a partir de consulta ejecutada en tiendas online internacionales

En la comercialización de plátano fresco se destacan países con mayor precio por $\mathrm{kg}$, como Alemania (USD 4,38),
Suiza (USD 4) y Países Bajos (USD 3,31). Los chips de plátano mostraron una tendencia de venta en bolsas y cajas 
plásticas con un peso neto entre $40 \mathrm{~g} \mathrm{y}$ $200 \mathrm{~g}$; se identifican diversos productos saborizados con cítricos, especias, sabores dulces y picantes. La papa fue el principal producto sustituto del plátano fresco y procesado, principalmente en chips, féculas, alimentos congelados y precocidos como puré, waffles y sopas. La valoración de esta etapa permitió seleccionar seis países con puntuaciones entre 86 y 92 puntos, que son: Estados Unidos (96), Suiza (91), México (92), Alemania (86), Países Bajos (86) y Chile (88).

Etapa 3. Selección de mercados: para los seis países seleccionados se aplicaron los criterios de ubicación geográfica y tiempos de tránsito, privilegiando países con una distancia corta o media desde Colombia; tiempos de tránsito máximos de 30 días; crecimiento económico y la cantidad y valor de las importaciones de productos procesados a base de plátano.

El mayor potencial de comercialización a corto plazo lo tienen Estados Unidos y Suiza; a medio plazo: México y Alemania; y a largo plazo: Países Bajos y Chile. El establecimiento de los plazos para el acceso al mercado se determina de acuerdo con las condiciones de producto, acceso por demanda de volumen y condiciones de los mercados.

El resultado final de la ponderación en la matriz de selección de mercados demostró que Estados Unidos es el país con mayor potencial para exportar los productos procesados a base de plátano, ya que tiene el PIB más alto de todos los mercados preseleccionados (USD 18.569.100 millones), la mayor cantidad de importaciones, en el año 2016, de plátano fresco $(354.806 \mathrm{t}) \mathrm{y}$ procesado (chips: 512.392 t; harina: 102.441 t; plátano congelado: 246.622 t); posee una ubicación e infraestructura portuaria y aeroportuaria que facilita el transporte por vía marítima y aérea con tiempos de tránsito máximos de 25 días desde Colombia.

\section{RESULTADOS}

Al examinar las tendencias de la industria alimenticia, cabe resaltar la influencia de la cultura extranjera en Norteamérica y Europa. Para Estados Unidos, como país más representativo, se analiza que los consumidores multiculturales componen el segmento de más rápido crecimiento que, de acuerdo con Nielsen (2016), reporta una variación del $92 \%$ entre el 2000 y 2014. En este contexto, los consumidores distribuidos entre afroamericanos, asiáticos, americanos e hispanos, influyen en el desarrollo de diferentes categorías de productos, inspirados en sabores relacionados con cada cultura y que se potencializan con la creación de un efecto "halo" en el resto de la población. Este análisis permite identificar oportunidades para productos procesados a base de plátano, dada su procedencia tropical caracterizada por una agricultura campesina y familiar. 
En los países productores africanos, el plátano aporta a la seguridad alimentaria y contribuye al crecimiento socioeconómico (Dzomeku, Dankyi \& Darkey, 2011); no obstante, la producción se ha visto disminuida por el aumento de plagas y enfermedades y los costos que implica su tratamiento (Viljoen, $\mathrm{Ku}$ nert, Kiggundu, Escalant \& Bornman, 2004). Igualmente, el comportamiento e importancia del cultivo del plátano en Colombia según la Organización de las Naciones Unidas para la Alimentación y la Agricultura - FAO (2011) así como su actual repunte, como analiza el Departamento Nacional de Estadística (DANE, 2018), el plátano es uno de los productos con mayor presencia en los sistemas productivos de la economía campesina y se constituye en un sector estratégico para el desarrollo rural.

De la misma manera y dado su valor nutritivo, la multiculturalidad de consumo y diversidad de preparaciones al vapor y cocinado (fritos o asados), así como snack o merienda en diversos momentos del día, validada en campo por la empresa Global Strategies \& Tools, abre la posibilidad para impulsar el desarrollo de la agroindustria con productos étnicos a base de plátano que ampliarían el portafolio de este sector y permitiría posicionar el plátano colombiano a mayor escala en países no productores del mismo.

Frente a las exportaciones, América Latina cuenta con grandes plantaciones dedicadas al comercio internacional, siendo el área Andina la de mayor potencial de exportación (Riojas, 2013). De esta manera, el aumento de las exportaciones de chips y de plátano congelado en Colombia es explicado por EAG Consultores (2016) y Pedraza (2017), en donde las tendencias en la alimentación en el mundo se han caracterizado por la búsqueda de comidas de fácil y rápida preparación, que se adaptan a un ritmo de vida acelerado que limita el tiempo de los consumidores, llevando así también al consumo de productos congelados que requieren de un tiempo corto de cocción.

La exportación representa un reto no solo desde la productividad de los cultivos, sino desde los procesos de transporte internacional, dado el rezago competitivo del país, ubicado en el puesto 66 entre 137 países, según el ranking publicado por Schwab en el marco del Foro Económico Mundial (2017), así como el atraso en infraestructura, cuyo desempeño logístico fue calificado con 2,67 en una escala de 1 a 5 por el mismo reporte. Esta situación se manifiesta en la desarticulación y desintegración de la infraestructura vial, la asignación de recursos y la inseguridad en el transporte que impactan de manera directa en el aumento de los costos logísticos (Pedraza, 2017).

En cuanto a las importaciones, en Estados Unidos el plátano ha adquirido gran importancia y reconocimiento gracias a que es catalogado como un producto saludable que puede reemplazar a la papa 
por a su alto contenido de almidones y vitaminas, según lo afirmado por EAG Consultores (2016), convirtiéndose en un producto representativo y con creciente potencial por ser libre de gluten. Comportamiento similar muestra el mercado de los chips de plátano, en el cual también actúan como sustitutos de la yuca, siendo demandados como snacks en restaurantes principalmente de origen latino, según la validación de mercado realizada por Global Strategies \& Tools (2017).

Por otro lado, la Unión Europea muestra un aumento en las importaciones de plátano como consecuencia de la reducción de aranceles a los países africanos y latinoamericanos, que les confiere un acceso preferencial al mercado (López, 2011). Durante el 2017, Ecuador entró a formar parte del acuerdo comercial existente entre la Unión Europea, Colombia y Perú. Igualmente, de acuerdo con FAO (2017), países como Nicaragua y Guatemala sobrepasaron los límites de exportación esperados hacia este bloque económico. De la misma manera se analiza que los países europeos presentan predilección hacia los alimentos naturales y orgánicos, que se refleja en una importación significativa de plátano fresco desde Latinoamérica, que representa otro reto para Colombia, cuya producción en orgánicos es aún muy baja.

Aumentar las exportaciones de productos a base de plátano implica un reto para los países productores, dado que los mercados de mayor crecimiento se encuentran a mayor distancia, con mayor tecnificación en empaques $\mathrm{y}$ embalajes y exigencias mayores en calidad y certificaciones para responder a la tendencia hacia el consumo de productos orgánicos, saludables y frescos, que adicionalmente representan el reto de optimizar la producción en microlotes y acceder al mercado con mayores márgenes.

La informalidad en la producción de plátano en economías con bajos niveles de desarrollo deteriora la posición competitiva de estos frente a comercializadores más estructurados y sofisticados, lo cual representa un reto en la generación de valor agregado a partir del escalamiento y al mismo tiempo en la introducción de modificaciones en la estructura de la cadena, transitando desde actividades simples a otras de mayor complejidad, según lo expuesto en el Manual fortalecimiento de cadenas de valor, financiado por la CEPAL en México (Padilla \& Oddone, 2017). Es así como las mesas sectoriales de competitividad se convierten en escenarios propicios para el fortalecimiento de cada uno de los eslabones de la cadena de valor del plátano, que apoyan el fortalecimiento de los procesos con mayor productividad y competitividad de las regiones.

La selección del mercado estadounidense como país con potencial para la exportación de plátano fresco y procesado, está fundamentada en el modelo de internacionalización del ciclo de 
vida del producto de Vernon (citado por Trujillo, Ospina, Guzmán \& Becerra, (2006, p. 6), en el cual se indica que las ventajas competitivas de las empresas se basan en su estructura de mercado y en una serie de factores que incluyen los ingresos per cápita, los salarios y demás indicadores que generan mayores ventajas productivas y de innovación. No obstante, la definición de criterios de selección y la escogencia del país norteamericano se justifica también en el modelo de Uppsala, al indicar que las empresas deben iniciar su internacionalización en mercados con menor distancia psicológica, gracias a que poseen un mayor conocimiento y experiencia que permiten comenzar su expansión a otros países con mayor distancia psicológica (Johanson \& Vahlne, 1977. p. 24).

\section{CONCLUSIONES}

El plátano es una oportunidad para el desarrollo rural en Colombia, dada la aptitud de la producción en el trópico, el conocimiento del cultivo, el número de productores involucrados (en su mayoría campesinos y de elaboración familiar), la priorización del cultivo en los planes de desarrollo locales y regionales, y la alta demanda de mercados sofisticados por productos naturales, autóctonos y con diversidad de sabores y texturas atractivos para un mercado dinámico y creciente, que debe buscar mayor participación en los beneficios generados por las cadenas de valor global.
Los productos elaborados a base de plátano tienen un procesamiento tradicional y artesanal, que facilita la transformación e industrialización de recetas con conocimientos ancestrales y étnicos que brindan experiencias diferenciadas por su combinación de sabores y texturas, que, a su vez, ofrecen salud y bienestar para diferentes estilos de vida, por sus características como el nulo contenido de gluten y altos niveles de almidón y potasio. La aplicación de nuevas tecnologías e ingredientes en el procesamiento puede tender a la potencialización del valor nutricional traducido en bienestar para el consumidor y el ambiente, gracias a las alternativas actuales para la utilización de los residuos que impulsan la sostenibilidad y rentabilidad de la cadena productiva.

Estados Unidos es el país que representa las mayores oportunidades de exportación del plátano en fresco y procesado a corto plazo para Colombia; sin embargo, para beneficiar este mercado y competir de manera significativa con los productos de Ecuador y Guatemala, es necesario implementar mejoras en calidad, variedad sembrada, volumen, manejo y trazabilidad del producto, de manera que responda de manera adecuada a las exigencias sanitarias y cantidades demandadas por los clientes internacionales.

El análisis de las cifras comerciales, tendencias $\mathrm{y}$ comportamiento del 
mercado de plátano en el ámbito internacional demuestra que el problema de la comercialización del plátano en este nivel no está dado por la baja demanda del producto, sino por el contrario, por la baja oferta exportadora de los países productores que no cumplen con los volúmenes para cubrir de manera simultánea con el consumo interno y la demanda progresiva del mismo en países como Estados Unidos y la Unión Europea, cuya población inmigrante presiona la demanda de este producto y difunde el consumo de un producto tan versátil como el plátano, percibido como un sustituto saludable para la papa y la yuca. 


\section{REFERENCIAS}

Asohofrucol. (2015). Se amplía la frontera hortifrutícola. Balance 2014. Neiva. Recuperado de www.asohofrucol.com.co

Bada, L. M., Rivas, L. A. \& Littlewood, H. F. (2017). Modelo de asociatividad en la cadena productiva en las mipymes agroindustriales. Contaduría y Administración, 62(4), 1100-1117. Recuperado de http://www.cya.unam.mx/index.php/ cya/article/view/977/908

Berden, K., Francois, J., Thelle, M., Wymenga, P. \& Tamminen, S. (2009). Non-Tariff Measures in EU-US Trade and Investment. An Economic Analysis. Rotterdam. Retrieved from www.ecorys.com

Campero, E. (2015). Las cadenas productivas como fuente de oportunidades para emprendedores en el medio rural. Innovación y Emprendimiento, 11(18), 75-85. https://doi.org/10.16925/in.v11i18.993

Cardozo, P. P., Chavarro, A. \& Ramírez, C. A. (2013). Teorías de internacionalización. Panorama, l(3). https://doi.org/10.15765/pnrm.vli3.264

Casson, M. \& Wadeson, N. (2017). Emerging Market Multinationals and Internalisation Theory. International Business Review, 27(6), 1150-1160. https://oi. org/10.1016/j.ibusrev.2018.04.006

Castro, A. M. (2007). Modelo de internacionalización para la empresa colombiana. Universidad Empresa, 6(12), 168-193. Recuperado de https://www.urosario. edu.co/urosario_files/28/2869b097-b644-4ff0-a57f-a660ea555c56.pdf

Conecta Rural. (2009). Situación actual y perspectivas del mercado del plátano. Recuperado de https://conectarural.org/sitio/material/situación-actual-y-pers pectivas-del-mercado-del-plátano

Congreso de Colombia. (2017). Ley 1876 del 29 de diciembre de 2017. Bogotá. Recuperado de http://es.presidencia.gov.co/normativa/normativa/LEY 1876 DEL 29 DE DICIEMBRE DE 2017.pdf 
Cuervo-Cazurra, A. (2018). Thanks but o Thanks: State-Owned Multinationals from Emerging Markets and Host Country Policies. Retrieved from https:// papers.ssrn.com/sol3/papers.cfm?abstract_id $=3298226$

Departamento Nacional de Estadística -DANE-. (2018). Boletín técnico producto interno bruto PIB cuarto trimestre de 2017 Cuentas trimestrales-colombia. Recuperado de https://www.dane.gov.co/files/investigaciones/boletines/pib/ bol_PIB_IVtrim17_oferta_demanda.pdf

Dzomeku, B. M., Dankyi, A. A. \& Darkey, S. K. (2011). Socioeconomic Importance of Plantain Cultivation in Ghana. The Journal of Animal \& Plant Sciences, 21(2), 269-273. https://doi.org/ISSN: 1018-7081

EAG, C. (2016). Plan estratégico de mercado: sector de musáceas. Manizales.

Flórez, D. H. (2017). Diseño de un modelo de articulación entre la cadena productiva hortofrutícola colombiana y la cadena logística de frío. Revista Temas Agrarios, 23(1).

Food and Agriculture Organization of the United Nations -FAO-. (2011). Colombia es el segundo importador de plátano del mundo. Retrieved from http://www. fao.org/in-action/agronoticias/detail/es/c/508466/

Food and Agriculture Organization of the United Nations -FAO-. (2017). Faostat. Retrieved from http://www.fao.org/faostat/en/\#data/QC

Francois, J. F., Berden, K., Tamminen, S., Thelle, M., Wymenga, P., Francois, J., ... Wymenga, P. (2013). Non-Tariff Measures in EU-US Trade and Investment: An Economic Analysis. Retrieved from https://econpapers.repec.org/paper/ lnzwpaper/20090806.htm

Global Strategy \& Tools. (2017). Informe de validación de mercado de musáceas en Nueva York. Manizales.

Grunert, K. G., Verbeke, W., Kügler, J. O., Saeed, F., \& Scholderer, J. (2011). Use of Consumer Insight in the New Product Development Process in the Meat Sector. Meat Science, 89(3), 251-258. https://doi.org/10.1016/J.MEATSCI.2011.04.024 
Innova Market Insights. (2015). Innova Market Insights Releases its 2016 Top Ten Trends List. Netherlands. Retrieved from https://www.newfoodmagazine. com/news/21011/innova-market-insights-announces-its-2016-top-ten-food-beverage-trends/

Johanson, J. \& Vahlne, J. E. (1977). The Internationalization Process of the Firm. A Model of Knowledge Development and Increasing Foreign Market Commitments. Journal of International Business Studies, 8(1), 23-32. https://doi. org/10.1057/palgrave.jibs. 8490676

Kasriel-Alexander, D. (2016). Top 10 Global Consumer Trends for 2016. London. Retrieved from https://staticl.squarespace.com/static/54caa57de4b09cd878bfa0c1/t/569682251115e0ac19d12dce/1452704299775/WP_Top-10GCT-2016_1.3-0116.pdf

López, C. (2011). La oferta comercial preferencial de la Unión Europea a los países en vías de desarrollo: modalidades e interacciones. Revista de Derecho Comunitario Europeo, 39(15), 443-483.

Macías, C. H. (2016). Descripción de la agrocadena del plátano en Colombia. Bogotá. Recuperado de http://repository.lasalle.edu.co/bitstream/handle/10185/18829/12072020_2016.pdf?sequence $=1$

Ministerio de Agricultura y Desarrollo Rural -MADR-. (2014). Cadena de plátano. Bogotá. Recuperado de www.minagricultura.gov.co

Ministerio de Agricultura y Desarrollo Rural -MADR-. (2016). Agronet. Estadisticas. Recuperado de https://www.agronet.gov.co/estadistica/Paginas/home. aspx?cod $=1 \#$

Mintel Group Ltda. (2017). Tendencias globales de alimentación y bebidas 2017. New York. Recuperado de https://es.mintel.com/tendencias-de-alimentacion -y-bebidas/2017

MintelGroupLtda. (2018). Tendencias globalesenalimentosybebidas 2018. New York. Recuperado de https://es.mintel.com/tendencias-de-alimentacion-y-bebidas/

Nielsen. (2016). What's in our Food and our Mind. Ingredient and Dining out Trends around the World. New York. Retrieved from https://www.nielsen.com/ 
content/dam/nielsenglobal/eu/docs/pdf/Global Ingredient and Out-of-Home Dining Trends Report.pdf

Olevsky, G., \& Dunska, M. (2014). Structural and Static Prerequisites for the Internationalization of Small and Medium. Sized Enterprises in the Baltic States. Procedia, Social and Behavioral Sciences, 110, 1209-1217. https://doi. org/10.1016/J.SBSPRO.2013.12.967

Padilla, R. \& Oddone, N. (2017). Manual para el fortalecimiento de cadenas de valor. México. Recuperado de https://repositorio.cepal.org/bitstream/ handle/11362/40662/1/S1601085_es.pdf

Pedraza, A. R. (2017). Caracterización del modelo de negocio del plátano en organizaciones de pequeños productores para el departamento de Córdoba, Colombia. Bogotá. Recuperado de http://repository.lasalle.edu.co/bitstream/ handle/10185/24865/86112206_2017.pdf?sequence=1\&isAllowed $=y$

Perfetti, J. J., Balcázar, A., Hernández, A. \& Leibovich, J. (2013). Políticas para el desarrollo de la agricultura en Colombia. Recuperado de www.bancoagrario. gov.co

Porter, M. E. (1998). The Competitive Advantage of Nations: With a New Introduction. Free Press.

Redacción El Tiempo. (2017). Productos agrícolas colombianos con potencial exportador. Recuperado de https://www.eltiempo.com/economia/sectores/ productos-agricolas-colombianos-con-potencial-exportador-37231

Riojas, C. (2013). El comercio exterior, la protoindustria y América Latina en el siglo XIX. Trace, (64). Recuperado de https://journals.openedition.org/trace/1182

Rodríguez, A. I., Baca, J., Santoyo, H. V. \& Reyes, J. (2013). Propuesta metodológica para analizar la competitividad de redes de valor agroindustriales. Revista Mexicana de Agronegocios, 32, 231-244. Recuperado de http://www.redalyc. org/articulo.oa?id=14125584007

Schwab, K. (2017). The Global Competitiveness Report 2017-2018 Insight Report. Geneva. https://doi.org/ISBN-13: 978-1-944835-11-8 
Stewart, T. A. (1998). La nueva riqueza de las organizaciones: el capital intelectual. Argentina: Granica.

Trade Wizards. (2018). Trade Wizards. Retrieved from http://www.lci.com.mx/tradewizards/Empresarial.aspx

Trademap. (2018). Trade Map. Estadísticas del comercio para el desarrollo internacional de las empresas. Recuperado de https://www.trademap.org/Index.aspx

Trujillo, M. A., Ospina, D. F., Guzmán, A. \& Becerra, G. (2006). Perspectivas teóricas sobre internacionalización de empresas. Bogotá: Universidad del Rosario. Recuperado de http://repository.urosario.edu.co/bitstream/handle/10336/1211/ BI 30.pdf

Trujillo, M. A. \& Guzmán, A. (2015). Revelación de información y valor de las empresas en América Latina. Bogotá: CESA-WBG. Recuperado de https://www. ifc.org/wps/wcm/connect/020379804a916ee182abcf9c54e94b00/Libro-Revelacion-Nov-13-2015.pdf?MOD=AJPERES

United Nations Conference on Trade and Development UNCTAD, Trust Fund on Market Information on Agricultural Commodities. (2016). Banana an Infocom Commodity Profile. New York and Geneva. Retrieved from https://unctad.org/ en/PublicationsLibrary/INFOCOMM_cp01_Banana_en.pdf

Vernon, R. (1979). The Product Cycle Hypoyhesis in a New International Environment. Oxford Bulletin of Economics and Statistics, 255-267. https://doi. org/10.1111/j.1468-0084.1979.mp41004002.x

Viljoen, A., Kunert, K., Kiggundu, A., Escalant, J. V., \& Bornman, C. H. (2004). Biotechnology for Sustainable Banana and Plantain Production in Africa: The South African Contribution. South African Journal of Botany, 70(1), 67-74. https://doi.org/10.1016/S0254-6299(15)30308-2

Williams, L. A. (2017). Top 10 Trends 2017 by Innova Market Insights. Netherlands. Retrieved from http://www.enfasis.com/Presentaciones/FTSMX/2017/ Summit_Food_Tech/FRIDA_KAHLO-TOP_TEN_TRENDS-LU_ANN_WILLIAMS.pdf 
World Customs Organization. (2016). WCO OMD-Harmonized System DataBase. Retrieved from http://harmonizedsystem.wcoomdpublications. org/?a_DisplayLanguage $=\mathrm{es}$

Zurbriggen, C. (2015). Hacia una nueva gobernanza: cocreación de iniciativas innovadoras para un desarrollo agrícola sostenible. Montevideo: Ciencias Sociales Universidad de la República de Uruguay. Recuperado de http://www. iica.int 


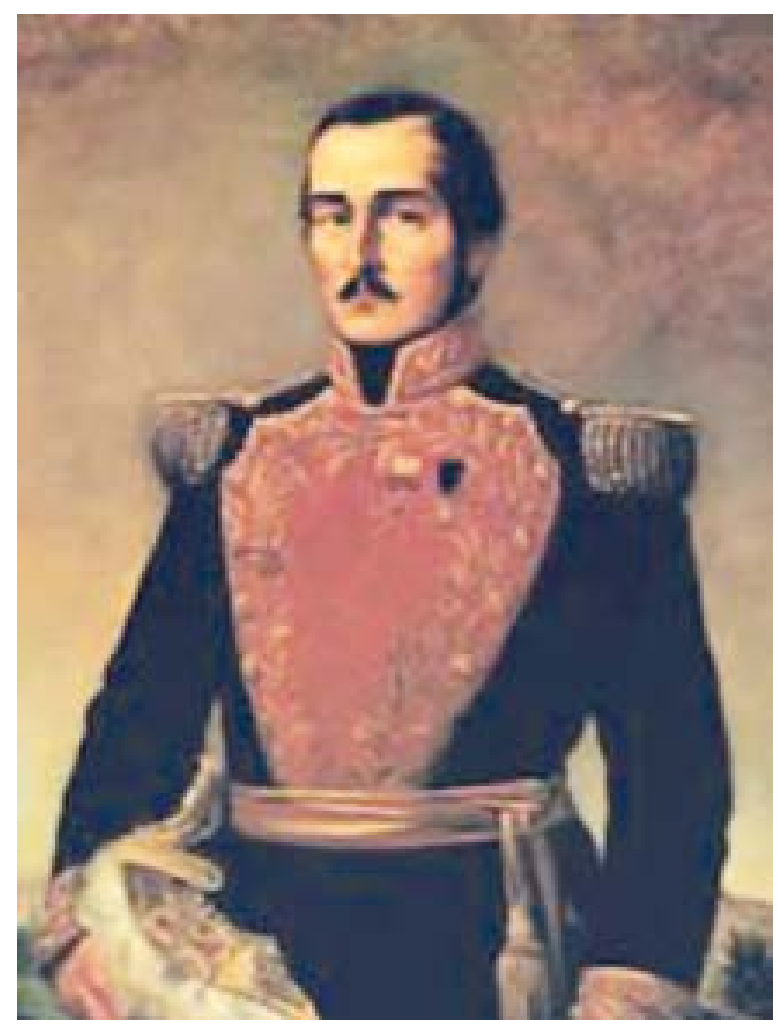

General Francisco de Paula Santander

\section{ECONOMÍA REGIONAL}


